\title{
Crack growth study under thermo-mechanical loads: parametric analysis for 2024 T3 aluminum alloy
}

\author{
Salmi Abdallah, Elajrami Mohamed \\ University of Djillali Liabès of Sidi Bel-Abbes, Algeria \\ salmiabdallab08@gmail.com, https://orcid.org/0000-0001-8352-8801 \\ eladjrami_mohamed@yahoo.fr \\ Mohamed El-Amine Slimani \\ University of Science and Technology Houari Boumediene, Bab-Ezzouar, 16111 Algiers, Algeria \\ mslimani@usthb.dr, https://orcid.org/0000-0002-8725-4892
}

ABSTRACT. Due to their severe operating conditions, many industrial components are subjected to complex combinations of cyclic mechanical stresses and thermal pressures. These combinations are responsible for the initiation and propagation of fatigue cracks in these parts, which can lead to failure. Thus, the study of the fatigue strength of these parts in such conditions becomes essential because it allows us to predict the life and safety of components.

This study examines the influence of the load ratio and temperature on the propagation rate of long cracks on the outer surface. The propagation of a fatigue crack in ABAQUS was therefore automatically simulated using an identified Paris law of 2024 T3 aluminum alloy. Therefore, the study of these components' fatigue resistance in such conditions becomes essential to predict the service life and safety of the components.

KEYwORDS. 2024 T3 aluminum alloy; Crack growth; Temperature; Finite elements; Thermo-mechanical fatigue.

\section{OPEN ACCESS}

Citation: Salmi, A., Elajrami, M., Slimani, M. E.A., Crack Growth Study Under Thermomechanical Loads: Parametric analysis for 2024 T3 aluminum alloy, Frattura ed Integrità Strutturale, 50 (2019) 231-241.

Received: 07.06.2019

Accepted: 16.08.2019 Published: 01.10.2019

Copyright: (C) 2019 This is an open access article under the terms of the CC-BY 4.0, which permits unrestricted use, distribution, and reproduction in any medium, provided the original author and source are credited.

\section{INTRODUCTION}

$\mathrm{T}$ o determine whether a crack is present in an equipment under thermo-mechanical loads, it is necessary, for obvious safety reasons, to identify accurately its harmfulness degree. When this crack spreads, under thermo-mechanical loads, it is important to quickly assess the evolution of this harmfulness degree and more concretely the residual life of the cracked structure. 
The resolution of this type of problem, within the framework of fracture mechanics, is carried out classically using the finite element method. But digital simulation of two-dimensional crack growth is challenging to simulate due to mesh-size reasons [1].

The asymptotic behavior of the displacement field in the vicinity of the crack front requires the local use of an extremely refined mesh size. Since the remeshing of the complete structure at each stage of the front is prohibitive, one solution is to isolate the discontinuity in a crack block, representing the strict vicinity of the crack, whose mesh size depends on the size of the defect and which can be inserted at any time into the rest of the structure, whose mesh size is fixed once and for all. We can mention, among others.

Dhondt [2] proposed an alternative solution for local remeshing with a generation of hexahedral elements at the crack passage, within the same framework as the finite element method. More generally, there are so-called "mesh-less" methods, which, in principle, make it possible to get rid of all the difficulties associated with mesh size, but at a higher price.

Jordan [3] studied the effect of the additional SDB (Slide Diamond Burnishing) parameters on the fatigue behavior of the 2024-T3 Al alloy has been studied experimentally. Samples of smooth, hourglass-shaped samples were blade-polished using different combinations of additional SDB parameters and then subjected to flexural fatigue tests. Residual stresses, introduced by the SDB, were measured by the X-ray diffraction technique. The microstructure close to the surface of the samples polished on a slide was studied. It has been established that the SDB produces two main effects, which depend on additional parameters of the SDB. The essence of the macro-effect is the creation of residual compressive stresses in the superficial and submarine layers. These constraints delay the formation and growth of fatigue macro cracks and thus increase the life of the polished components per blade.

Monotonic tests were performed From KarakaŞ and Szusta [4] to determine the influence of temperature on the mechanical properties of the material. The purpose of the cyclic tests was to acquire the parameters required for the Manson-Coffin equation in order to plot the stress-fatigue life curves. In addition, the stress-strain behavior of the alloy and the cyclic hardening behavior were evaluated using the Ramberg-Osgood equation. The results obtained indicate that the fatigue life is reduced when the operating temperature increases.

Punith Gowda [5] reveals the study of the mechanical properties of Al2024-tungsten carbide MMCs (Metal Matrix Composites) containing tungsten carbide (WC) particles. The reinforcing particles in Al2024 alloy ranged from $0 \%$ to 5\% by weight. The results of this study revealed that as the tungsten carbide particle content increased, tensile strength, hardness, and Young modulus, compressive strength, increased. Significantly, accompanied by a reduction in ductility.

Mohammad Zaki [6] reveals the influences of anodizing parameters of Al 2024 T3 in TSA (Tartaric-Sulphuric Acid) on the thickness, the weight and corrosion resistance of the anodized layer are studied. The corrosion resistance test was performed by running a salt spray test for 336 hours and anodic polarization measurements using a potentiostat. The results of showed that the most important factor in determining the thickness and weight of the anodized layer is the temperature, followed by the applied voltage, the voltage-temperature interaction, the temperature and the duration of the layer [6].

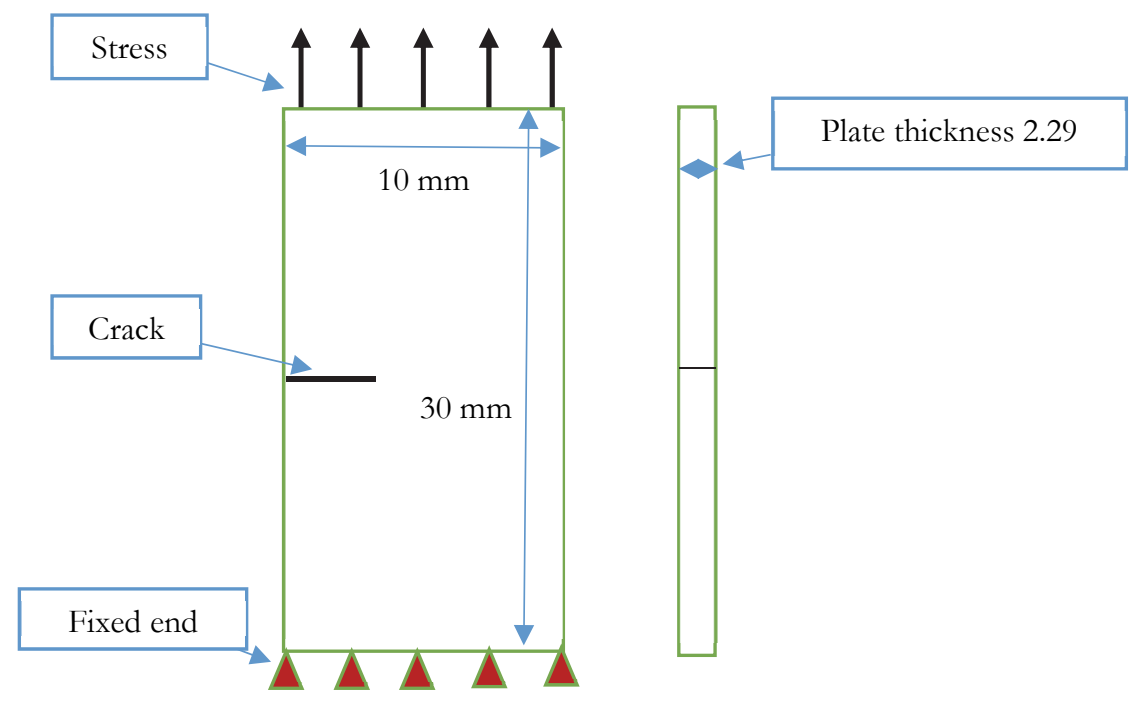

Figure 1: Sample $(30 \mathrm{~mm} * 10 \mathrm{~mm} * 2.29 \mathrm{~mm})$ 
This study presents a tool for simulating the crack growth in thermo-mechanically loaded equipment. This tool is based on the crack block concept and aims to minimize the cost of meshing operations, which are prevalent in this type of application. Moreover, this work is based on the creation of a program in Python language using the advantages of the Abaqus calculation codes, chosen for their respective flexibility in terms of mesh size and geometric modeler, in the absence of a versatile tool. The reminder of the article is organized as follows: Section 2 describes the material used to conduct this study. Section 3 discusses the results and, finally, section 4 summarizes the results of this work and draws conclusions.

To study the characteristics of long-standing cracks, all tests were performed in ambient air with a frequency of $10 \mathrm{~Hz}$ [7] and under sinusoidal loading of constant amplitude $118 \mathrm{MPa}$ [8], with a load ratio $\mathrm{R}$ between 0.1 and 0.7.

The purpose of these tests is to characterize the behavior of long cracks in the case of $2024 \mathrm{~T} 3$ aluminum alloy plates by determining the propagation threshold and the Parisian law coefficients. Initial crack size $a_{\text {init }}=5.08 \mathrm{~mm}$ capable spread to a critical final size $\mathrm{a}=7.18 \mathrm{~mm}$. Fig. 1 shows the sample $(30 \mathrm{~mm} * 10 \mathrm{~mm} * 2.29 \mathrm{~mm})$ exposed to an initial temperature of $20^{\circ} \mathrm{C}$.

This study focuses on the behavior of an external crack, since the rate of crack propagation is more severe [9].

\section{STUDY MATERIAL}

\section{4-T3 alloy}

he 2024 alloy is a copper magnesium aluminum alloy with a high copper content of up to 4\% by mass. Generally, impurities such as iron and silicon are always present in the composition. In addition to the precipitation hardening, fine particles of size $\approx 100 \mathrm{~nm}$ formed during heat treatment, alloy 2024 also contains intermetallic particles. These particles are much larger than the hardening precipitates; they are formed during processing and have no effect in the curing process.

On the other hand, they have an important role in the phenomena of localized corrosion. Baog et al. [10] estimated that the density of intermetallic is in the order of 300,000 particles $/ \mathrm{cm}^{2}$.

The microstructure of these alloys becomes very complex given the difference in composition and the different forms of this intermetallic, which are of two types:

- The particles S (Al2CuMg): according to Bechet et al. [11], the particles S represent $60 \%$ of the intermetallic particles present in the alloy 2024-T3. They have a rounded shape, with sizes ranging from 1 to $5 \mu \mathrm{m}$ [12].

-The particles of Al-Cu-Fe (Mn): several authors have worked on the characterization of these particles according to their size and their chemical composition [10, 11, and 13]. Al-Cu-Fe (Mn) particles are generally larger than S-phase particles, with sizes ranging from 10 to $25 \mu \mathrm{m}$ and irregular shapes.

Tab. 1 summarizes the intermetallic particles of this type present in the 2024-T3 alloy.

\begin{tabular}{lc}
\hline Composition & Reference \\
Al7CuFe2 & {$[10,13]$} \\
Al12 (Fe, Mn) 3Si & {$[14]$} \\
$\mathrm{Al} 6(\mathrm{Fe}, \mathrm{Cu}, \mathrm{Mn})$ & {$[11,13,14]$} \\
$(\mathrm{Al}, \mathrm{Cu}) 6 \mathrm{Mn}$ & {$[11,13]$} \\
$\mathrm{Al} 6 \mathrm{MnFe} 2$ & {$[11]$} \\
$\mathrm{Al} 20(\mathrm{Cu}, \mathrm{Fe}, \mathrm{Mn}) 5 \mathrm{Si}$ & {$[10]$} \\
\hline
\end{tabular}

Table 1: Synthesis of the different intermetallic compounds of the Al-Cu-Fe (Mn) type present in alloy 2024-T3

\section{Elastoplastic behaviour}

Tab. 2 presents the standard elastic properties of Aluminum 2024 T3 [15].

\begin{tabular}{cccccc}
\hline $\begin{array}{c}\text { Modulus of } \\
\text { Elasticity } \\
(\mathrm{GPa})\end{array}$ & $\begin{array}{c}\text { Poisson } \\
\text { coefficient }\end{array}$ & $\begin{array}{c}\text { Coefficient of thermal } \\
\text { expansion }(\mathrm{mm} / \mathrm{m} * \mathrm{k})\end{array}$ & $\begin{array}{c}\text { Thermal Conductivity } \\
(\mathrm{w} / \mathrm{m} * \mathrm{k})\end{array}$ & $\begin{array}{c}\text { Specific Heat } \\
\text { Capacity }\left(\mathrm{j} / \mathrm{kg}^{*} \mathrm{k}\right)\end{array}$ & $\begin{array}{c}\text { Density } \\
\left(\mathrm{g} / \mathrm{cm}^{3}\right)\end{array}$ \\
73 & 0.33 & 22.8 & 120 & 870 & 2.77 \\
\hline
\end{tabular}

Table 2: Mechanical properties of 2024-T3 aluminum alloy 
Tab. 3 provides the 2024T3 aluminum alloy chemical compositions [4].

\begin{tabular}{lllllllll}
\hline Material & $\mathrm{Cu}$ & $\mathrm{Fe}$ & $\mathrm{Si}$ & $\mathrm{Cr}$ & $\mathrm{Mg}$ & $\mathrm{Mn}$ & $\mathrm{Zn}$ & $\mathrm{Ti}$ \\
2024-T3 & 4.82 & 0.18 & 0.07 & 0.02 & 1.67 & 0.58 & 0.06 & 0.15 \\
\hline
\end{tabular}

Table 3: Chemical composition by mass in percentage.

\section{RESULTS AND DISCUSSION}

$\mathrm{P}$

aris and Erdogan have constructed a quantitative framework of fatigue fracture mechanics, which correlates the fatigue crack growth rate to the range of stress intensity factor as follows [16]:

$$
\frac{d a}{d N}=C \Delta K^{m}
$$

where $\mathrm{C}$ and $\mathrm{m}$ are empirical material constants, $\Delta \mathrm{K}=\mathrm{K}_{\max }-\mathrm{K}_{\min }$ is the stress intensity factor range in fatigue loading, $N$ is number of cycles, and $d a$ is crack extension length.

The following correlation gives the relation between $\mathrm{C}$ and $\mathrm{m}$ parameters:

$$
\log C=a+b m
$$

$\mathrm{a}$ and $\mathrm{b} \prec 0$

where: $\mathrm{a}$ is the ordinate at the origin and $\mathrm{b}$ is the slope of the regression line.

Or

$$
\mathrm{C}=\frac{A}{B^{m}}
$$

$$
\text { with } \mathrm{A}=10^{a}=\left(\frac{d a}{d N}\right)_{p} \quad \mathrm{~B}=10^{-b}=\Delta \mathrm{k}_{p}
$$

$\left[\left(\frac{d a}{d N}\right)_{p}\left(\frac{m m}{c y c l e}\right) ; \Delta k_{p}(\operatorname{MPa} \sqrt{m})\right] \quad$ Coordinates of the pivot point [17].

The material constants in Paris equation depicted in Tab. 4 [18]:

\begin{tabular}{cc}
\hline Plate thickness $2.29 \mathrm{~mm}$ & Plate thickness $6.35(\mathrm{~mm})$ \\
$\mathrm{m}=3.2828$ & $\mathrm{~m}=4.224$ \\
$\mathrm{C}=3.63 \mathrm{E}-13$ & $\mathrm{C}=1.51 \mathrm{E}-15$ \\
\hline
\end{tabular}

Table 4: Material constants in Paris law for aluminum panel.

The total number of stress cycles $\mathrm{N}$ required for a short crack to propagate from the initial crack length $\mathrm{a}_{0}$ to any crack length a can then be determined as

$$
N=\sum_{i=1}^{z} N_{i}
$$

$N_{i}$ stress cycles required for the appearance of the initial crack $i=1 ; 2 ; 3 ; \ldots ; z$

$z$ number of grains transverse by the crack 
When the crack extends over ten or more grains, the influence of the material structure on the growth of the crack becomes negligible and the theory of mechanics of linear elastic fracture can be applied later [19].

In this simple form, the presence of a growth threshold of fatigue cracks and a limit greater than $\Delta \mathrm{K}$ (stress intensity factor range) for the fracture are not shown, although, if appropriate, expressions taking into account these limits, as well as the influence of the load ratio of the cycle $\mathrm{R}=\mathrm{P}_{\min } / \mathrm{P}_{\max }$ can be easily found in the literature.

\section{LOAD RATIO INFLUENCE}

$\mathrm{F}$ ig. 2 shows the curves representing the cracking rate versus the stress intensity factor range for the different load ratios studied. Fig. 2 indicates that the propagation rates vary according to the load ratio.

The load ratio effect is very important, in fact, the propagation rate at $\mathrm{R}=0.3$ is much higher than at $\mathrm{R}=0.1$ in the

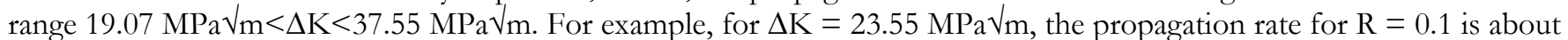
$9.89 \mathrm{E}-5 \mathrm{~m} /$ cycle, while it is more than twice as high for $\mathrm{R}=0.3(\mathrm{da} / \mathrm{dN}=1.11 \mathrm{E}-4 \mathrm{~m} /$ cycle). The same observations can be made if the different load ratios $\mathrm{R}=0.3$ and $\mathrm{R}=0.4$ are compared. $\mathrm{R}=0.4$ and $\mathrm{R}=0.5$ and finally $\mathrm{R}=0.5$ and $\mathrm{R}=0.7$.

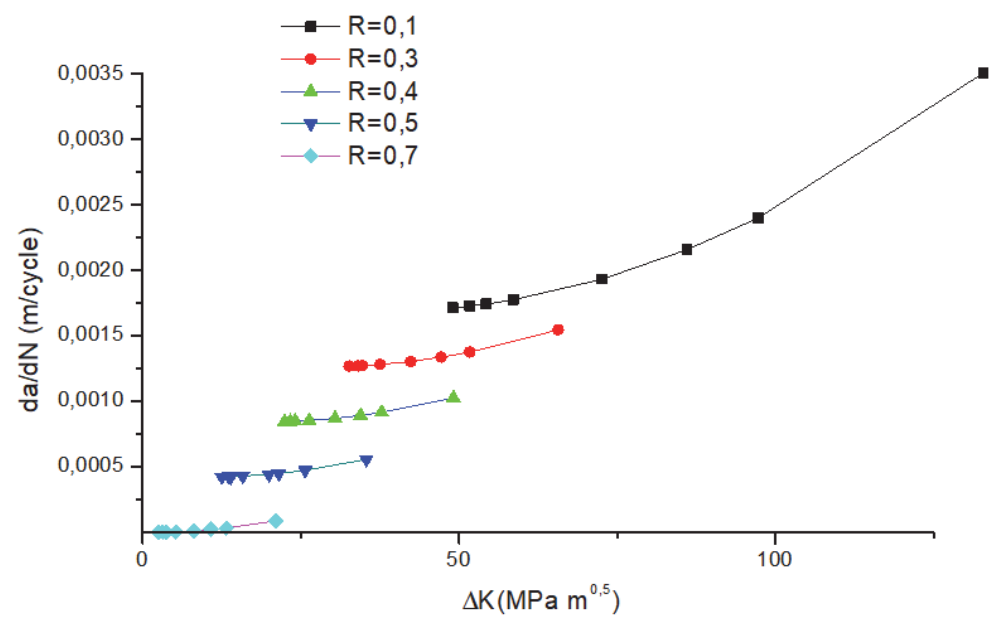

Figure 2: Load ratio influence on crack propagation

The impact of the load ratio $\mathrm{R}(0.1,0.3,0.4,0.5$ and 0.7$)$ was verified. Indeed, the load ratio effect has a very significant impact on the crack propagation rate of the $2024 \mathrm{~T} 3$ aluminum alloy.

To study the influence of the load ratio on the propagation time of a fatigue crack, Fig. 3 shows the propagation of a $5 \mathrm{~mm}$ crack as a function of the number of cycles for load ratios $0.1,0.3,0.4,0.5$ and 0.7 under a maximum stress of $118 \mathrm{MPa}$.

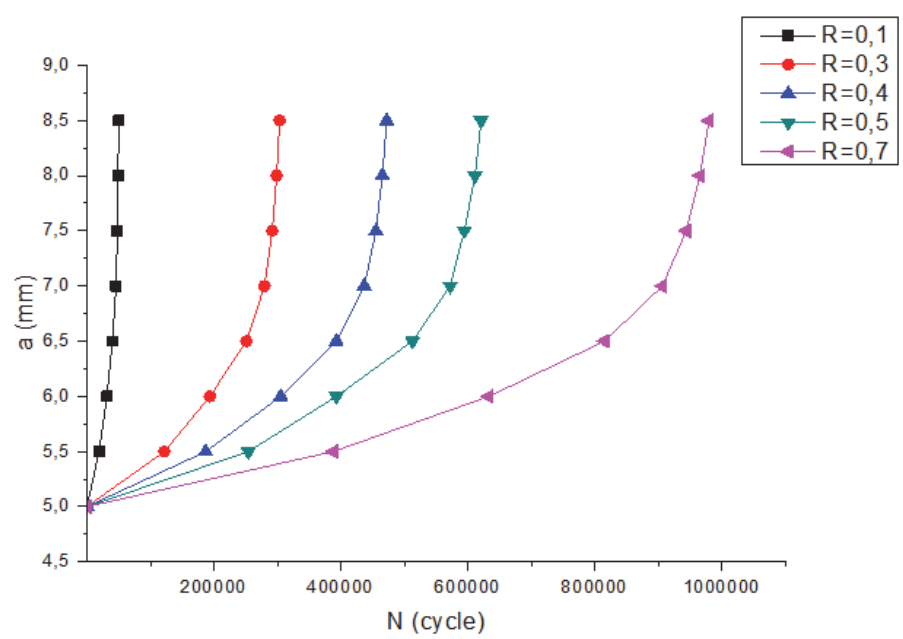

Figure 3: Propagation time of a $5 \mathrm{~mm}$ crack for different load ratios. 
The results show that the number of cycles increases with the load ratio, that is the higher the load ratio, the greater the cracking resistance at the same maximum stress.

We also note that:

The paper presents a computational model for determining the lifetime of crack propagation for 2024 T3 aluminum alloy. The fatigue process is divided into crack initiation $(N i)$ and crack propagation $(N p)$ periods, which allows the total lifetime to be determined as

$$
N=N i+N p
$$

\section{INFLUENCE OF TEMPERATURE}

hese results present a digital calculation of the plate. Thermal and mechanical results are exposed respectively.

\section{Thermal results}

Fig. 4 shows the temperature changes as a function of the x-position in the thickness.

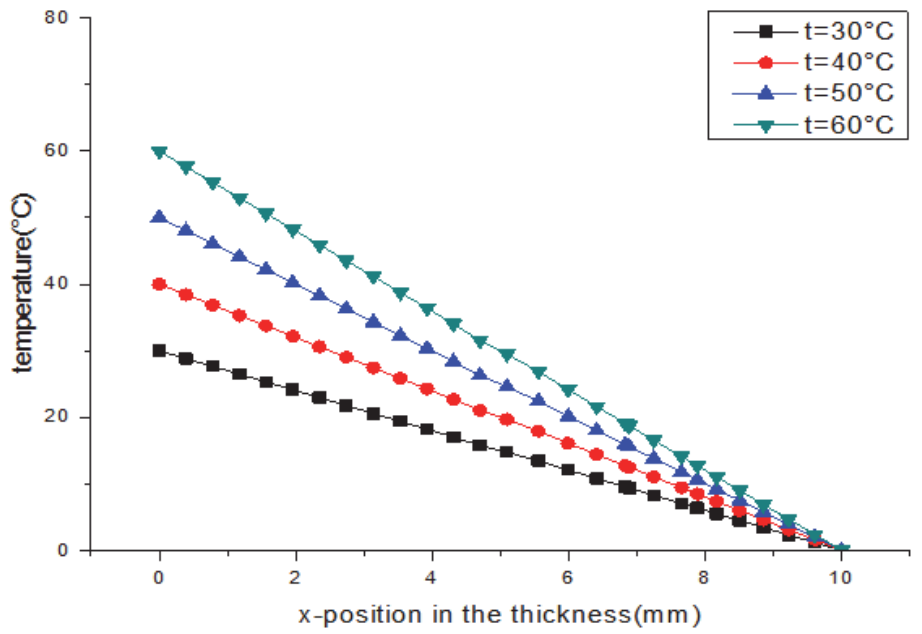

Figure 4: Temperature changes as a function of the x-position in the thickness at different temperatures

These results show that the thermal gradient in the thickness continues by conduction and decreases during the inner face of the plate. the temperature field in the plate has been well estimated by our calculations.

\section{Mechanical results}

This section presents the results of the calculation with a model in which the mechanical behaviour of each phase is of the elasto-plastic type with linear cinematic hardening.

The axial displacement variations follow the thickness are represented by the Figs. $5<\mathrm{A}(\mathrm{a}=5.08 \mathrm{~mm}) ; \mathrm{B}(\mathrm{a}=5.50 \mathrm{~mm}) ; \mathrm{C}$ $(\mathrm{a}=6.34 \mathrm{~mm}) ; \mathrm{D}(\mathrm{a}=7.18 \mathrm{~mm})>$ for differing temperatures at crack widths ranging from 5.08 to 7.18.

On the one hand in Fig. 5:

- we note that for each $\mathrm{x}$-position in thickness, when the temperature increases from $+30^{\circ} \mathrm{C}$ to $+60^{\circ} \mathrm{C}$, the changes in the very high axial displacement is more apparent for crack widths greater than $7.18 \mathrm{~mm}$.

- On the other hand, for a $\mathrm{x}$-position in thickness and constant temperature, with an increase in crack width from a=5.08mm to $7.18 \mathrm{~mm}$, the changes in axial displacement increase.

Deformation variations according to thickness are illustrated in Fig. $6<\mathrm{A}(\mathrm{a}=5.08 \mathrm{~mm}) ; \mathrm{B}(\mathrm{a}=5.50 \mathrm{~mm}) ; \mathrm{C}(\mathrm{a}=6.34 \mathrm{~mm}) ; \mathrm{D}$ $(a=7.18 \mathrm{~mm})>$ to differentiate temperatures at crack widths ranging from 5.08 to $7.18 \mathrm{~mm}$.

These results also indicate that:

- The overall deformations of the plate increase significantly, when the thermal and mechanical aspect are coupled.

- Overall, compared to the thermo-mechanical growth cases presented above, the overall deformations of the plate are less well simulated in this case. 
The equivalent stress variations according to Vos- Mises follow thickness are represented by the Figs. $7<\mathrm{A}(\mathrm{a}=5.08 \mathrm{~mm})$; $\mathrm{B}(\mathrm{a}=5.50 \mathrm{~mm}) ; \mathrm{C}(\mathrm{a}=6.34 \mathrm{~mm}) ; \mathrm{D}(\mathrm{a}=7.18 \mathrm{~mm})>$ to differ from temperatures at crack width between 5.08 and $7.18 \mathrm{~mm}$.



A

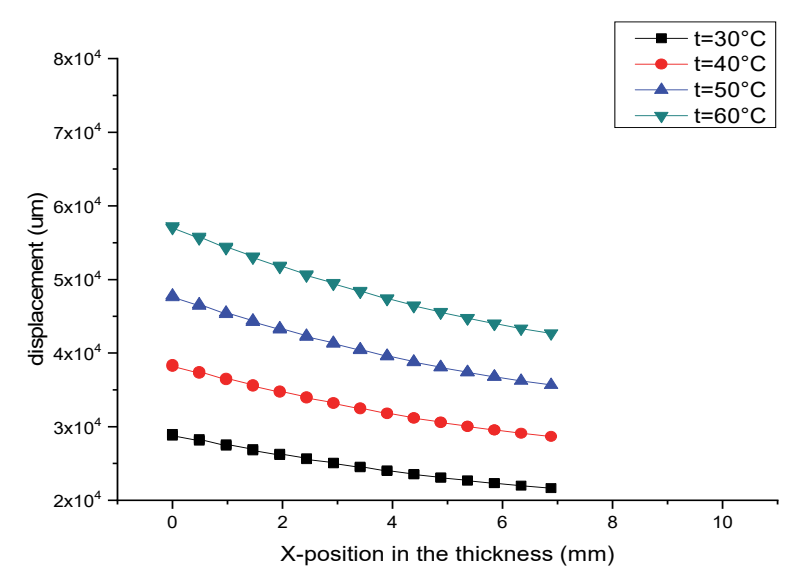

C

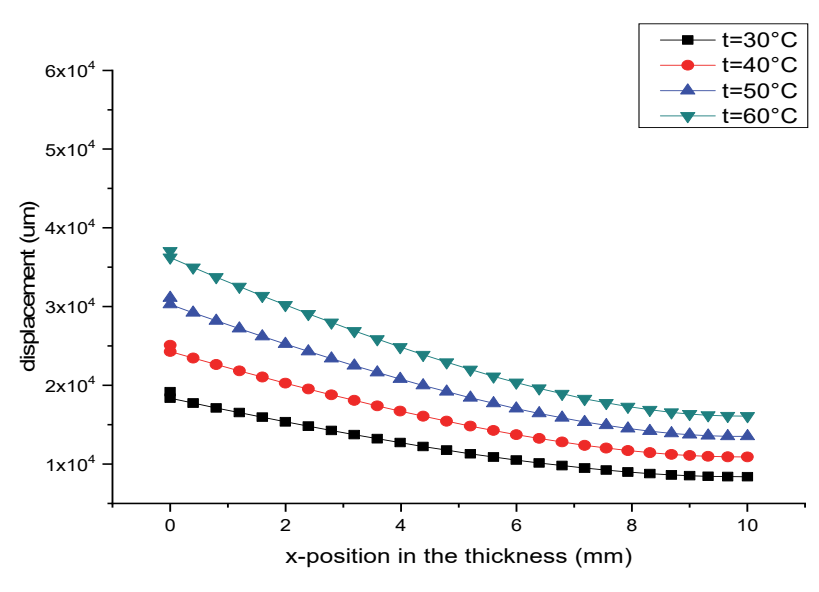

$\mathrm{B}$

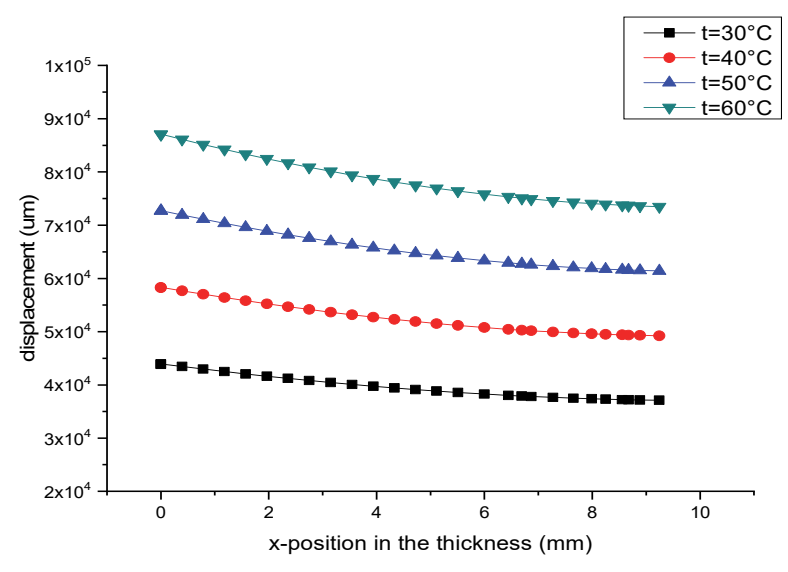

$\mathrm{D}$

Figure 5: Variations in axial displacement follow from the x-position in the thickness at different temperatures

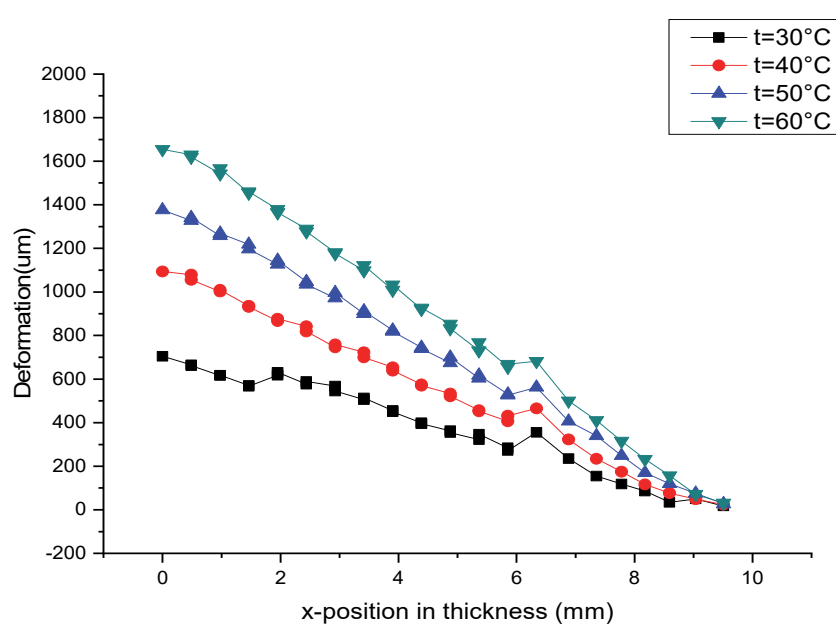

A

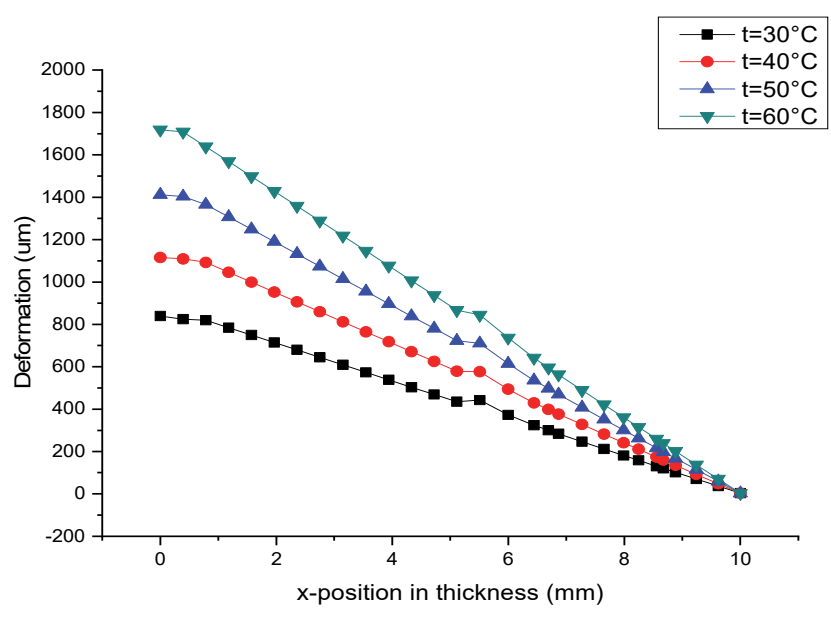

$\mathrm{B}$ 


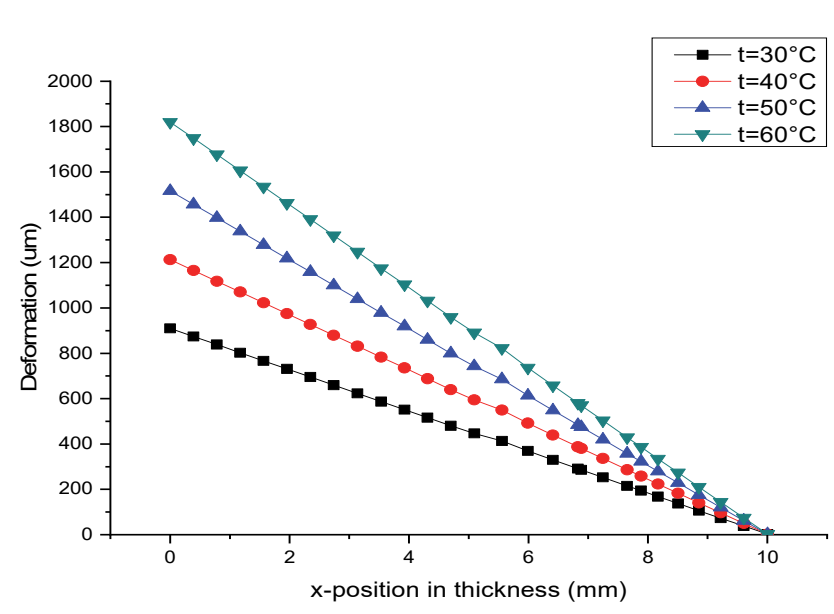

C

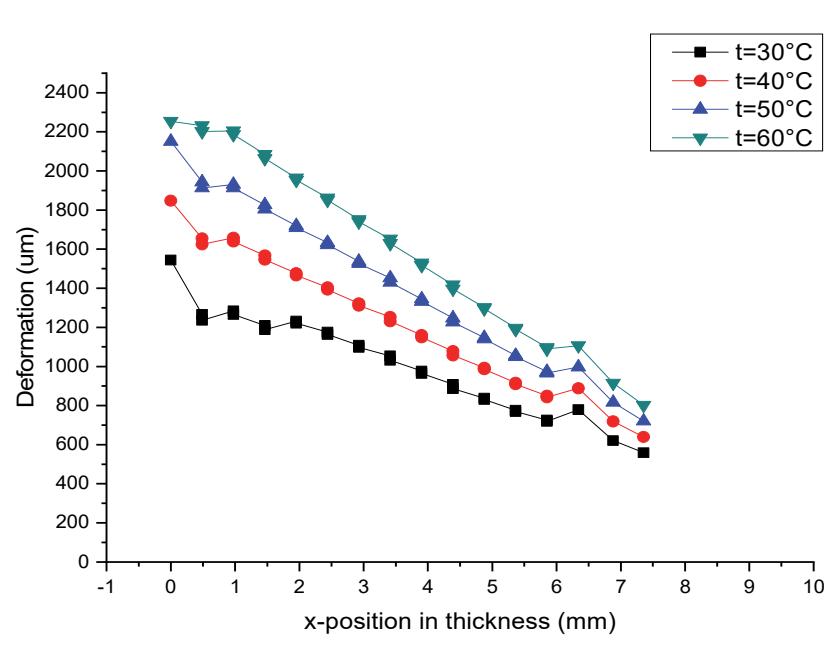

$\mathrm{D}$

Figure 6: Deformation variations determined from the x-position in thickness to various temperatures

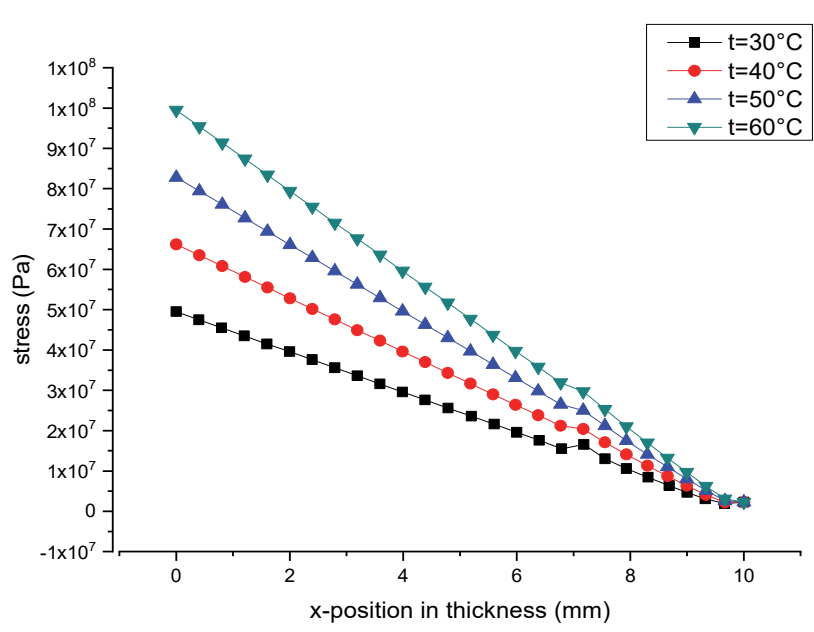

A



C

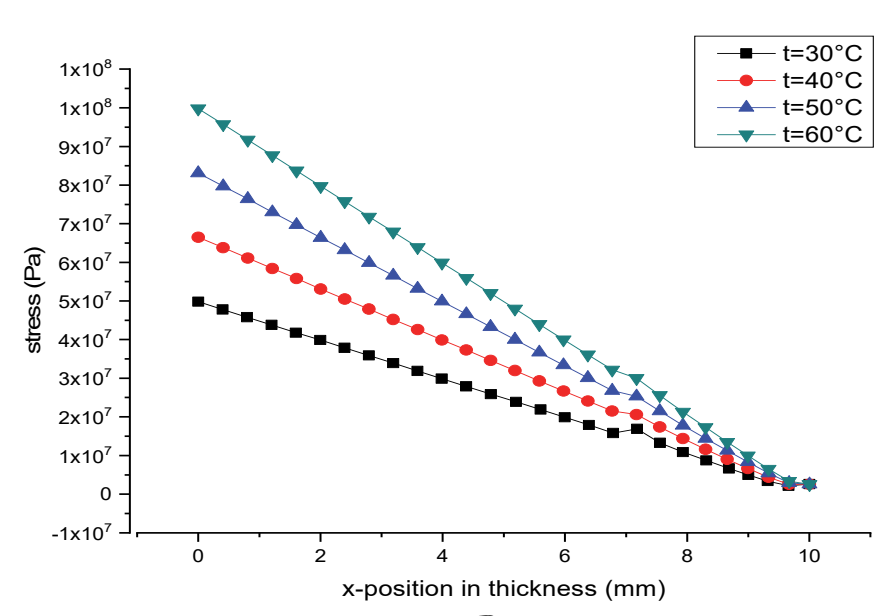

B

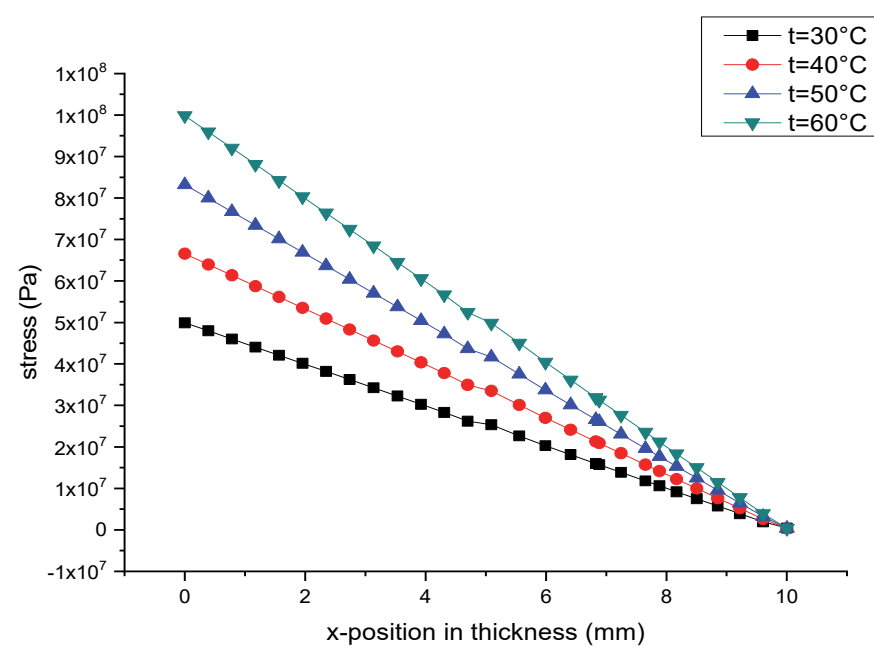

$\mathrm{D}$

Figure 7: Variations in equivalent stress according to Vos- Mises following from x-position in thickness to various temperatures

We also note that: 
Maximal value of the Von-Mises stress due to the thermo-mechanical effect is located at the level of the crack axis.

Stress distribution is very different with singularities at the x-position in the thickness. In an aluminum alloy plate, the stresses range from $0 \mathrm{MPa}$ to $100 \mathrm{MPa}$. The difference is quite significant, around $20 \mathrm{MPa}$, so we can observe the good thermal and mechanical behavior.

Decrease in stress on the inside edge.

If the temperature increases, the equivalent stress increases at any temperature, which validates the published results.

Variations in equivalent stress according to Vos-Mises as a function of axial displacement are represented in Figs. $8<\mathrm{A}$ $(a=5.08 \mathrm{~mm}) ; \mathrm{B}(\mathrm{a}=5.50 \mathrm{~mm}) ; \mathrm{C}(\mathrm{a}=6.34 \mathrm{~mm}) ; \mathrm{D}(\mathrm{a}=7.18 \mathrm{~mm})>$ at different temperatures for crack width between 5.08 and 7.18 .



A

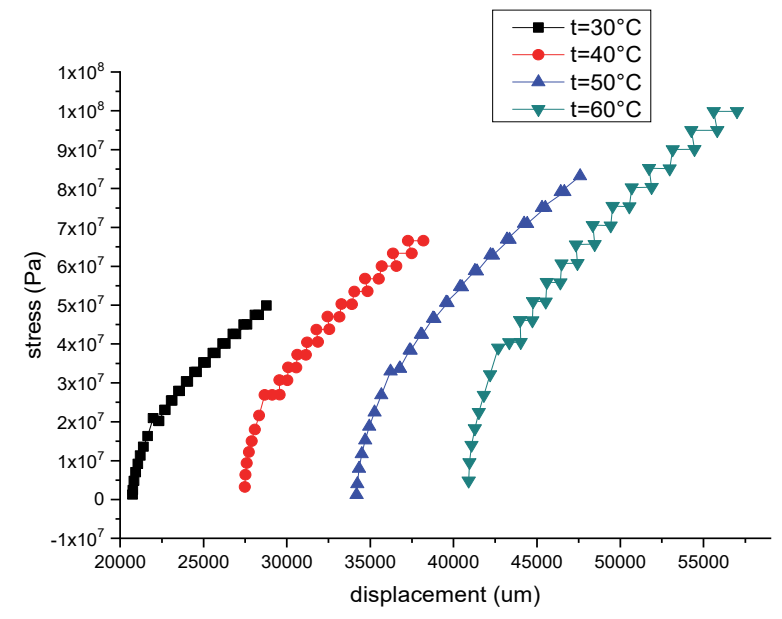

C

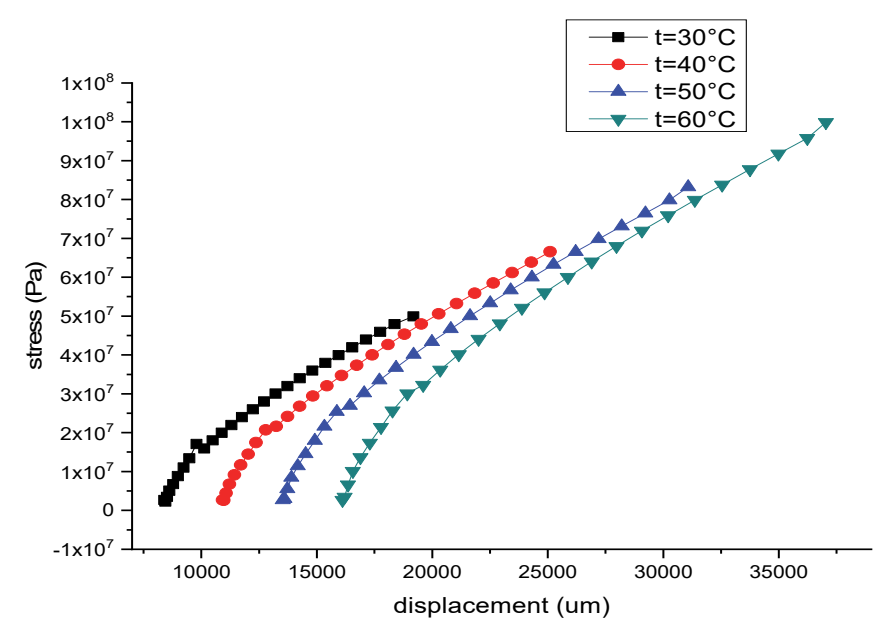

B

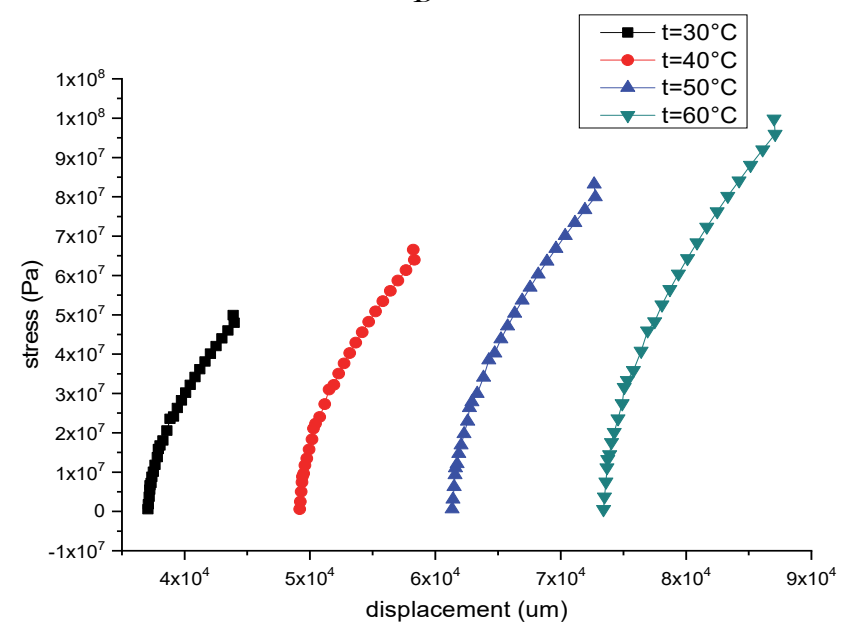

$\mathrm{D}$

Figure 8: Variations in equivalent stress according to Von-Mises as a function of axial displacement at different temperatures

\section{CONCLUSIONS}

he obtained results reveal a difference in behaviour at the selected node levels relative to the conditions imposed by the proposed model. Thermo-mechanical input was found to show a significant increase in stress relative to the elasticity threshold of this 2024 T3 aluminum alloy, relative to mechanical input.

The following conclusions can be made:

- The proposed model is used to determine the number of Ni loading cycles required to initiate fatigue damage through certain loading cycles and the introduction of adequate material fatigue parameters. The method used for numerical 
modelling and the possibility of predicting the initiation of fatigue damage in mechanical elements following a cyclic contact solicitation represent this contribution to the problems examined.

- The qualitative effect of load ratio is to shift a growth rate curve along a line passing through the inflection points. The observation that this shift is not horizontal forms the basis for stress ratio modeling with the hyperbolic sine When the curve is completed.

- The use of the appropriate mechanical behavior laws for the different phases of thermo-mechanical growth plays an important role in the mechanical results, in particular on the distribution of residual stresses in the structure. Thus, the increase in temperature leads to an increase in the equivalent stresses of Von-Mises, axial displacements and total deformation of the plates.

- The Thermo-mechanical effect occurring at the conditions of the performed tensile, depends on the temperature and the direction of sampling concerning the plate rolling direction. The effect occurs even at such low temperature as $30^{\circ} \mathrm{C}$ and is most in-tense in the temperature range $50-60^{\circ} \mathrm{C}$.

- Von-Mises stresses and overall deformations and plate contact pressures increase significantly when the thermal and mechanical aspect is coupled.

- The effect of temperature on crack propagation is presented, giving the best lifetime prediction.

- The damage becomes more pronounced with higher temperature

Finally, it is important to note that the "strong" coupling between temperature and mechanical variables (stress, strain, strain, and damage) is very important. Temperature considerations in plastic or visco-plastic models allow the behaviour of structures to be well represented without complex loads. Additional analyses should be conducted to assess the applicability and limitations of the methodology for studying cases in which significant behavior of plastic deformation is involved.

\section{ACKNOWLEDGEMENTS}

7 he authors are especially grateful for the support provided by the Laboratory (LMS). Department of Mechanical Engineering, Faculty of Technology, University Djillali Liabès of Sidi Bel-Abbes, Algeria and Research Unit in renewable energies in the desert center adrar, Algeria.

\section{REFERENCES}

[1] Chapuliot, S. (2000). Formulaire de KI pour les tubes avec un défaut de surface semi-elliptique longitudinal ou circonférentiel, interne ou externe, Direction des Réacteurs Nucléaires. Rapport de recherche., CEA R-5900.

[2] Dhondt, G. (1998). Cutting of a 3D finite element mesh for automatic mode I crack propagation calculations, International Journal for Numerical Methods in Engineering., 42, pp. 749-772. DOI: 10.1002/(SICI)1097-0207.

[3] Jordan, T.M., Angel, P.A., Galya, V.D., Nikolaj, G., Kenan, F.S. and Vladimir, P.D. (2018). Impact of slide diamond burnishing additional parameters on fatigue behaviour of 2024 -T3 Al alloy, Fatigue Fract Eng Mater Struct., 42, pp. 111. DOI:10.1111/ffe.12915.

[4] KarakaŞ, Ö. and Szusta, J. (2016). Monotonic and low cycle fatigue behaviour of 2024-T3 aluminum alloy between room temperature and $300{ }^{\circ} \mathrm{C}$ for designing VAWT components, Fatigue Fract Engng Mater Struct., 39, pp. 95-109. DOI: $10.1111 /$ ffe.12336.

[5] Gowda, P., Prakash, K., Shivashankare Gowda, J.N., and Satish Babu, B. (2015). Effect of Particulate Reinforcement on the Mechanical Properties of Al2024-WC MMCs, Journal of Minerals and Materials Characterization and Engineering, 3, pp. 469-476. DOI: 10.4236/jmmce.2015.36049.

[6] Zaki, M., Wahab, M., Sutarno and Wahyudi, S. (2015). Effects of Anodizing Parameters in Tartaric-Sulphuric Acid on Coating Thickness and Corrosion Resistance of Al 2024 T3 Alloy, Journal of Minerals and Materials Characterization and Engineering, 3, pp. 154-163. DOI: 10.4236/jmmce.2015.33018.

[7] Manti, R., Dwivedi, D.K. and Agarwal, A. (2008). Pulse TIG welding of two Al-Mg-Si alloys, Journal of Materials Engineering and Performance, 17, pp. 667-673. DOI: 10.1007/s11665-008-9210-z.

[8] Abdullah, S., Beden, S.M. and Ariffin, A.K. (2011). Fatigue crack growth simulation of aluminum alloy under cyclic sequence effects, In Tech Pub., 247. DOI: 10.5772/14898.

[9] Guedri, A. (2008). Conception et simulation numérique des caractéristiques mécaniques des pipelines, Ph.D. thesis, université badji Mokhtar. Annaba. Algeria. 
[10] Boag, A., Hughes, A.E., Wilson, N.C., Torpy, A., MacRae, C.M., Glenn, A.M. and Muster, T. (2009). How complex is the microstructure of AA2024-T3, Corros. Sci., 51(8), pp. 1565-1568. DOI: 10.1016/j.corsci.2009.05.001.

[11] Buchheit, R., Grant, R., Hlava, P., Mckenzie, B. and Zender, G. (1997). Local dissolution phenomena associated with $\mathrm{S}$ phase $(\mathrm{Al} 2 \mathrm{CuMg})$ particles in aluminum alloy 2024-T3, Journal of the Electrochemical Society, 144(8), pp. 2621-2628. DOI: $10.1149 / 1.1837874$.

[12] Liao, C.M., Olive, J., Gao, M. And Wei, R. (1998). In-situ monitoring of pitting corrosion in aluminum alloy 2024, Corrosion., 54(6), pp. 451-458. DOI: 10.5006/1.3284873.

[13] Guillaumin, V. and Mankowski, G. (1999). Localized corrosion of 2024 t351 aluminum alloy in chloride media, Corros. Sci., 41(3), pp. 421-438. DOI: 10.1016/S0010-938X(98)00116-4.

[14] Starke Jr, E. and Staley, J. (1996). Application of modern aluminum alloys to aircraft, Prog Aerosp Sci., 32(2-3), pp. 131-172. DOI: 10.1016/0376-0421(95)00004-6.

[15] Hénaff, G. (2005). Fatigue des matériaux et des structures, Cours ENSMA, Poitiers, France.

[16] Alihosseini, H., Dehghani, K. and Faraji, G. (2014). Simulation of Fatigue Life Behavior of Circular Cross-Section Bar with Straight-Fronted Crack, Modeling and Numerical Simulation of Material Science., 4, pp. 128-135. DOI: $10.4236 / \mathrm{mnsms} .2014 .43014$.

[17] Wang, H. (1997). Contribution à l'étude de l'influence des paramètres de chargement sur la modélisation de la propagation de fissure par fatigue sous amplitude de chargement constant, Ph.D. thesis, University of Science and Technology of Lille.

[18] Hosseini-Toudeshky, H., Mohammadi, B., Sadeghi, G. and Daghyani, H.R. (2007). Numerical and experimental fatigue crack growth analysis in mode-I for repaired aluminum panels using composite material, Composites., Part A. 38(4), pp. 1141-1148. DOI: 10.1016/j.compositesa.2006.06.003.

[19] Glodez, S. and Flasker, J. (1997). Model utrujanja zobnih bokov z upoštevanjem parametrov mehanike loma A Fracture Mechanics Model of Gear Flanks Fatigue, Journal of Mechanical Engineering, 43(5-6), pp. 203-218. 